\title{
Grey Correlation Analysis Of The Development Impact Of Ningbo Logistics Industry Factors
}

\author{
WangWei ${ }^{1, a}$ \\ ${ }^{1,}$ Beijing Wuzi University, Beijing, China \\ a Wangwei199304@126.com
}

Key words: Port Throughput; GDP; the degree of association; Ningbo

\begin{abstract}
With strong bearing transport and logistics port throughput capacity, mainly integrated logistics center in Ningbo City, it has been the people most concerned about the size of the rapid development of its logistics industry today its port throughput is inextricably linked. Ningbo port handling more trade, but the contribution of the various sectors of the local GDP to development is not balanced, the degree of association studies Ningbo nine kinds of industry factors and its port throughput in this paper by using gray relational grade analysis method, analysis the result of low food industry and port throughput relevance of the reasons given reasonable improvement methods, leads to local business environment is poor logistics, warehousing, logistics equipment behind, logistics and transport convergence multiple problems such as poor management, thereby obtaining recommendations Ningbo improve the current situation, from heavy industry development of traditional acceleration to moderately heavy direction transformation, promote exchanges and learning among enterprises, attracting high water for the personnel, accelerate the establishment of food base, encourage enterprises to enhance the logistics outsourcing service awareness, put forward only a single aspects of the pursuit of GDP index, but would like the new concept of green GDP goal.
\end{abstract}

\section{Introduction}

Ningbo has always been one of many scholars of the key areas of its port throughput is worthy of continued study, found the problem and solve the problem, with the rapid economic promotion, has a "transportation hub," said the Ningbo City, port handling the case remains original condition ${ }^{[1]}$, the main industry of Ningbo port throughput has not changed, the main logistics and transport projects has not changed, Ningbo logistics industry contain a large number of port throughput, mainly petroleum and petroleum products, metals minerals, machinery, light industry, medicine, coal and related products industries. There are many researchers using appropriate methods of analysis, the factors affecting the development of the logistics industry have done a lot of research and analysis, Li Xiaogang and Huang Xufeng (2010) two scholars' Ya City Statistical Yearbook "as the basis, the use of 11 factors of raw data obtained gray correlation degree of each factor, draw a variety of factors for the logistics industry in Quzhou influence is not high, and made Quzhou logistics industry in order to pay attention to the rapid development of logistics resources must proceed from the elements ${ }^{[2]}$. Li Yi-yang (2011) in Gansu Province industry, for example, the use of gray correlation coefficient and correlation of results for local tertiary industry GDP, the largest ${ }^{[3]}$. 
Wang Huanhuan and Sun Bo (2011) structural model based on interpretation of the principle of ISM, factors that will affect the development of the logistics industry in China has established reachability matrix, after several transformation will affect the relationship between the original complex, into a simple-to-understand diagrams, and propose a reasonable solution for the primary and secondary factors ${ }^{[4]}$. Di Chen Feng (2011) using the stationary test and cointegration analysis, with a large number of text data throughput of Ningbo port, econometric model, analyze and correct errors, obtained Ningbo port throughput for the local GDP growth has important practical significance ${ }^{[5]}$. High-Sheng and Zhang Xi Wind (2013) The two researchers for the development of Zhejiang factors affect intensive studies on five major indicators 17 aspects of the introduction method of gray correlation analysis, yield important contributing factor to the development of local logistics ${ }^{[6]}$. Huang Han (2013) raised the level of the manufacturing industry, the degree of urbanization, infrastructure situation, the online retail market deal size and other factors affecting the development of China's logistics industry, gray relational analysis method derived manufacturing and development level of China Logistics Industry the greatest correlation, and finally how to optimize the development of the logistics industry in our country gives sound advice ${ }^{[7]}$. Tian Zhenzhong (2014) using path analysis study for logistics industry development in Henan Province, by calculating the path coefficients, the direct comparison of the effect of various factors affected the logistics industry, the indirect effect and the combined effect of ${ }^{[8]}$. Based on the above research scholars, further throughput of Ningbo port to conduct the gray system analysis, drawn from various sectors related to the degree of development of local GDP, reveals various local logistics industry development, as well as the development of the logistics industry the extent of the contribution of the local GDP. Finally, how rational allocation of various sectors of the logistics industry to accelerate the development of standards and focus concept.

\section{Ningbo Port Throughput with Grey Correlation Analysis of GDP Growth}

According to "Ningbo Statistical Yearbook 2014" in the gross production of the calendar year as economic growth in GDP of Ningbo City, the main reference data, this paper Ningbo Economic Growth in GDP as reference data matrix V, the important port throughput of nine indicators, including coal and coal products, petroleum and petroleum products, metal ores, chemical raw materials and products, iron and steel, mineral building materials, non-metallic ores, salt, and grain as a comparison matrix port throughput $\mu 1, \mu 2$

$\mu$. Its data in Table 1 below.

Table 1 2008-2014 Ningbo Port Throughput situation and GDP Data Sheet

(Unit: 10,000 tons, million)

\begin{tabular}{|l|l|l|l|l|l|l|l|l|}
\hline factor & & 2008 & 2009 & 2010 & 2011 & 2012 & 2013 & 2014 \\
\hline GDP & $\mathbf{V}$ & 3946.52 & 4334.33 & 5181.00 & 6074.94 & 6601.21 & 7164.51 & 7610.28 \\
\hline $\begin{array}{l}\text { Coal and } \\
\text { Related } \\
\text { Products }\end{array}$ & $\boldsymbol{\mu}_{\mathbf{1}}$ & 4673 & 4789 & 6121 & 6560 & 6631 & 7926 & 7413 \\
\hline petroleum & $\boldsymbol{\mu 2}$ & 6897 & 7567 & 8054 & 8588 & 7445 & 8090 & 7982 \\
\hline Metal ores & $\boldsymbol{\mu 3}$ & 7215 & 7626 & 7490 & 7262 & 8348 & 8929 & 10220 \\
\hline
\end{tabular}




\begin{tabular}{|l|l|l|l|l|l|l|l|l|}
\hline Chemicals & $\boldsymbol{\mu 4}$ & 944 & 1119 & 1224 & 1291 & 1319 & 1339 & 1388 \\
\hline Steel & $\boldsymbol{\mu 5}$ & 781 & 813 & 953 & 899 & 928 & 1078 & 992 \\
\hline $\begin{array}{l}\text { Mineral } \\
\text { building } \\
\text { materials }\end{array}$ & $\boldsymbol{\mu 6}$ & 904 & 1170 & 1983 & 1474 & 1901 & 1994 & 1882 \\
\hline $\begin{array}{l}\text { Non-metallic } \\
\text { ore }\end{array}$ & $\boldsymbol{\mu 7}$ & 360 & 348 & 380 & 390 & 362 & 466 & 480 \\
\hline salt & $\boldsymbol{\mu 8}$ & 78 & 66 & 106 & 99 & 115 & 114 & 135 \\
\hline \multicolumn{1}{c|}{ food } & $\boldsymbol{\mu 9}$ & 209 & 240 & 252 & 223 & 199 & 177 & 201 \\
\hline
\end{tabular}

As can be seen from the table intuitive, various industries for the local GDP impact of greater value, increased tedious calculations, and each business unit is not consistent, in order to facilitate the calculation and correct data processing, data needs to be dimensionless processing, data can be in different units into a single form, which you can ignore the impact of various factors of different units brought problems. Since the 2008 Olympic Games is held in Beijing, will increase to a certain extent on the economic development of the region, 2008 will be used as the starting data, gray related degree method will make the first data no great influence, which can have a representative, Therefore, this paper will be the economic value of the GDP in 2008 and nine industry factors as the initial value of port throughput, data subsequent six years.

According V0 (k) and $\mu \mathrm{i}(\mathrm{k})$ gray correlation coefficient formula can draw the following formula:

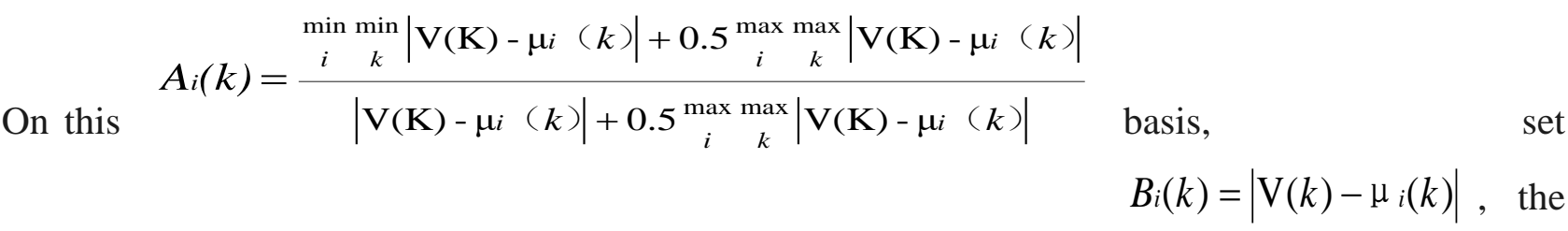
GDP reference value by economic factors and by nine factors made the difference between absolute value whichever is later, and the results are shown in Table 2.

Difference processing data in Table 2

\begin{tabular}{|l|l|l|l|l|l|l|l|l|}
\hline factor & & 2008 & 2009 & 2010 & 2011 & 2012 & 2013 & 2014 \\
\hline GDP & $\mathbf{V}$ & 0.0000 & 0.0000 & 0.0000 & 0.0000 & 0.0000 & 0.0000 & 0.0000 \\
\hline $\begin{array}{l}\text { Coal and } \\
\text { Related } \\
\text { Products }\end{array}$ & $\boldsymbol{\mu}_{\mathbf{1}}$ & 0.0000 & 0.0735 & 0.0029 & 0.1355 & 0.2537 & 0.1193 & 0.3421 \\
\hline petroleum & $\boldsymbol{\mu 2}$ & 0.0000 & 0.0012 & 0.1450 & 0.2941 & 0.5932 & 0.6424 & 0.7711 \\
\hline Metal ores & $\boldsymbol{\mu 3}$ & 0.0000 & 0.0413 & 0.2747 & 0.5328 & 0.5157 & 0.5778 & 0.5119 \\
\hline Chemicals & $\boldsymbol{\mu 4}$ & 0.0000 & 0.0871 & 0.0162 & 0.1717 & 0.2755 & 0.3970 & 0.4581 \\
\hline Steel & $\boldsymbol{\mu 5}$ & 0.0000 & 0.0573 & 0.0926 & 0.3882 & 0.4845 & 0.4351 & 0.6582 \\
\hline
\end{tabular}




\begin{tabular}{|l|l|l|l|l|l|l|l|l|}
\hline $\begin{array}{l}\text { Mineral } \\
\text { building } \\
\text { materials }\end{array}$ & $\boldsymbol{\mu 6}$ & 0.0000 & 0.1959 & 0.8808 & 0.0912 & 0.4302 & 0.3904 & 0.1535 \\
\hline $\begin{array}{l}\text { Non-metallic } \\
\text { ore }\end{array}$ & $\boldsymbol{\mu 7}$ & 0.0000 & 0.1316 & 0.2572 & 0.4560 & 0.6671 & 0.5210 & 0.5951 \\
\hline salt & $\boldsymbol{\mu 8}$ & 0.0000 & 0.2521 & 0.0462 & 0.2701 & 0.1983 & 0.3539 & 0.1976 \\
\hline \multicolumn{1}{c|}{ food } & $\boldsymbol{\mu 9}$ & 0.0000 & 0.0500 & 0.1071 & 0.4723 & 0.7205 & 0.9685 & 0.9667 \\
\hline
\end{tabular}

The resulting new gray correlation coefficient formula after substituting into the above equation is $B_{i}(k)$

$$
A_{i}(k)=\frac{\min _{i}^{\min } B_{i}(k)+0.5{ }_{i}^{\max \max _{k}} B_{i}(k)}{B_{i}(k)+0.5{ }_{i}^{\max \max _{k}} B_{i}(k)}
$$

From the data in Table 3, the difference in treatment, we can see the data in Table 3 is the biggest difference, After taking the average of each data can be drawn various factors associated with the gray level of the size of GDP, the data in Table 3.

Table 3 factors and GDP Grey Relational Data

\begin{tabular}{|l|l|l|l|l|l|l|l|l|l|}
\hline factor & $\mathbf{W}_{\mathbf{1}}$ & $\mathbf{W}_{\mathbf{2}}$ & $\mathbf{W}_{\mathbf{3}}$ & $\mathbf{W}_{\mathbf{4}}$ & $\mathbf{W}_{\mathbf{5}}$ & $\mathbf{W}_{\mathbf{6}}$ & $\mathbf{W}_{\mathbf{7}}$ & $\mathbf{W}_{\mathbf{8}}$ & $\mathbf{W}_{\mathbf{9}}$ \\
\hline Correlation & 0.8126 & 0.6649 & 0.6374 & 0.7506 & 0.6770 & 0.6787 & 0.6151 & 0.7443 & 0.6144 \\
\hline
\end{tabular}

By calculating the impact of nine kinds of gray correlation degree data throughput of the port city of Ningbo factors can be drawn W1 $=0.8126$, W2 $=0.6649$, W3 $=0.6374, \mathrm{~W} 4=0.7506$, W5 $=0.6770$, $\mathrm{W} 6=0.6787, \quad \mathrm{~W} 7=0.6151, \quad \mathrm{~W} 8=0.7443, \quad \mathrm{~W} 9=0.6144, \quad$ Its order is $\mathrm{W} 1>\mathrm{W} 4>\mathrm{W} 8>\mathrm{W} 6>\mathrm{W} 5>\mathrm{W} 2>\mathrm{W} 3>\mathrm{W} 7>\mathrm{W} 9$, This is illustrated in Ningbo logistics industry relations for logistics and transportation of coal and its products and services to its closest port throughput, the local GDP growth contribution maximum and the minimum degree of association of food factors and throughput of the port, indicating the food industry production and logistics $B_{9}(6)=0.9685$ Ningbo economic contribution is small yet become the major logistics and transport business, $\mathrm{V}(1)=\mathrm{V}(2)=\mathrm{V}(3)=\mathrm{V}(4)=\mathrm{V}(5)=\mathrm{V}(6)=\mathrm{V}(7)=0 \quad$ food industry did not become one of the key object of attention of local businesses, resulting in the food industry, transportation and logistics services not high quality, low-ranking port throughput results. Ningbo affected local economic factors, policy factors and business factors, equipment and facilities, also have taken most of the transport mode of road transport, while rail transport and pipeline transport are of little use, so the maximum throughput of the port of coal, but Some metal ores and non-metallic minerals due to its large cargo, load transport vehicles they need to have strong features, such as modes of transport rail transport is more suitable metal ores and non-metallic minerals such goods, the only way to play an effective role in the economy.

\section{Conclusion}

According to "Ningbo Statistical Yearbook 2014" shows that From 2010 to 2014 the share of rail transport management over the years the percentage of cargo were $6.74 \%, 8.16 \%, 5.90 \%, 6.12 \%$, 
5.85\% per year are ranked in the railway, highway and water transport of the last three, This shows that rail transport has seriously hampered the development of Ningbo logistics transportation. In addition, some petroleum and its products due to its having explosive characteristics, it must consider the transport of people, goods, financial security, are more suitable for pipeline transport of oil that type of energy transport, but Ningbo pipeline transport use inefficient, thus impeding the development of local logistics and transport oil in this type of energy, resulting in contribution to the local GDP growth is small.

\section{References}

[1] Yin Weizhong, Fuwei Qin Ningbo integrated transport hub construction and integration measures [J] Communications Standardization, 2013,21: 51-54.

[2] Li Xiaogang, Huang Xufeng Grey factors Regional Logistics Development - A Case Study of Quzhou City [J] Economic Industrial Technology, 2010,01: 121-123.

[3] Wang Huanhuan, Sun Bo China's development of the logistics industry influence factors explain the structure of the model [J] Shandong Institute of Business and Technology, 2011,01: 12-16.

[4] Grey correlation Industrial Structure and Economic Growth in Gansu Province Li Yi Yang [J] enterprise economy, 2011,05: 20-23.

[5] Chen Feng Di throughput of Ningbo Port and Ningbo economic impact of empirical analysis [J] reform and opening up, 2011,16: 117-118.

[6] Huang Han Factors Affecting China Logistics Industry Development - A case study model of gray correlation analysis [J] Based Logistics Technology, 2013,09: 261-263.

[7] high-Sheng, the development of regional logistics factors influence Grey Correlation Zhang Xi wind Zhejiang Province [J] Railway Transport and Economy, 2013,09: 49-53.

[8] TIAN Zhen-based development impact of logistics factors Henan Path Analysis [J] Zhengzhou University (Natural Science Edition), 2014,01: 111-114 + 120. 